The hope is that the results of these investigations will give rise to the development of novel and reproducible strategies to induce donor-specific immunologic tolerance that can be translated effectively from rodent models to primates and ultimately humans ${ }^{1}$.

1. Salama, A.D., Remuzzi, G., Harmon, W.E. \& Sayegh, M.H. Challenges to achieving clinical transplantation tolerance. J. Clin. Invest. 108, 943-948 (2001).

2. Kreisel, D. et al. Non-hematopoietic allograft cells directly activate $\mathrm{CD} 8^{+} \mathrm{T}$ cells and trigger acute rejection: an alternative mechanism of allorecognition. Nature Med. 8, 233-239 (2002).

3. Sayegh, M.H. \& Turka, L.A. The role of T cell costimulatory activation in transplant rejection. $N$. Engl. J. Med. 338, 1813-1821 (1998).

4. Krensky, A., Weiss, A., Crabtree, G., Davis, M. \& Parham, P. T-lymphocyte-antigen interactions in transplant rejection. N. Engl. J. Med. 322, 510-517 (1990).

5. Auchincloss, H.J. et al. The role of "indirect" recognition in initiating rejection of skin grafts from major histocompatibility complex class II-de- ficient mice. Proc. Natl. Acad. Sci. USA 90, 3373-3377 (1993).

6. Lee, R.S. et al. Indirect recognition of allopeptides promotes the development of cardiac allograft vasculopathy. Proc. Natl. Acad. Sci. USA 98, 3276-3281 (2001).

7. Briscoe, D.M., Alexander, S.I. \& Lichtman, A.H. Interactions between $\mathrm{T}$ lymphocytes and endothelial cells in allograft rejection. Curr. Opin. Immunol. 10, 525-531 (1998).

8. Randolph, G.J., Beaulieu, S., Lebecque, S., Steinman, R.M. \& Muller, W.A. Differentiation of monocytes into dendritic cells in a model of transendothelial trafficking. Science 282, 480-483 (1998).

9. Denton, M.D., Geehan, C.S., Alexander, S.I., Sayegh, M.H. \& Briscoe, D.M. Endothelial cells modify the costimulatory capacity of transmigrating leukocytes and promote CD28-mediated $\mathrm{CD4}^{+} \mathrm{T}$ cell alloactivation. J. Exp. Med. 190, 555-566 (1999)

10. Epperson, D.E. \& Pober, J.S. Antigen-presenting function of human endothelial cells. Direct activation of resting CD8 T cells. J. Immunol. 153, 5402-5412 (1994)

11. Biedermann, B.C. \& Pober, J.S. Human endothelial cells induce and regulate cytolytic $T$ cell differentiation. J. Immunol. 161, 4679-4687 (1998).
12. Lakkis, F.G., Arakelov, A., Konieczny, B.T. \& Inoue, $Y$. Immunologic 'ignorance' of vascularized organ transplants in the absence of secondary lymphoid tissue. Nature Med. 6, 686-688 (2000).

13. Trambley, J. et al. Asialo GM1(+) CD8(+) T cells play a critical role in costimulation blockade-resistant allograft rejection. J. Clin. Invest. 104, 1715-1722 (1999).

14. Yamada, A., Salama, A.D. \& Sayegh, M.H. The role of novel $\mathrm{T}$ cell costimulatory pathways in autoimmunity and transplantation. I. Am. Soc. Nephrol. 13, 559-575 (2002).

15. Marelli-Berg, F.M. et al. Major histocompatibility complex class II-expressing endothelial cells induce allospecific nonresponsiveness in naive $T$ cells. J. Exp. Med. 183, 1603-1612 (1996).

16. Marelli-Berg, F.M. et al. Activated murine endothelial cells have reduced immunogenicity for $\mathrm{CD}^{+} \mathrm{T}$ cells: a mechanism of immunoregulation? J. Immunol. 165, 4182-4189 (2000).

Brigham and Women's Hospital and

Children's Hospital

Harvard Medical School

Boston, Massachusetts, USA

Email: msayegh@rics.bwh.harvard.edu

\title{
Shrinking genes for therapy
}

Gene therapy holds great promise for treating many genetic diseases. But what happens if the gene to be 'fixed' is just too big to be delivered to the affected tissue? Researchers have tried to get over the obstacle by creating reduced versions of large genes, such as the 2.4-megabase dystrophin gene that is mutated in patients with Duchenne muscular dystrophy (DMD). A study in this issue uses micro-dystrophin constructs to correct the DMD phenotype in a mouse model of the disease, suggesting that gene therapy of DMD might be feasible.

There is currently no treatment for DMD, a lethal X-linked disease caused by mutations that eliminate production of the muscle protein dystrophin or result in truncated, nonfunctional versions of the protein. Muscles lacking functional dystrophin (in particular, skeletal limb, cardiac and diaphragm muscles) are susceptible to mechanical damage and progressively degenerate. The dystrophin-deficient $m d x$ mouse provides an animal model to study DMD.

Based on previous structure-function analyses of different portions of dystrophin in transgenic $m d x$ mice, Jeffrey Chamberlain, Scott Harper and colleagues at the University of Washington School of Medicine generated extremely small dystrophins with similar function to that of the full-length protein. The authors then tested their micro-dystrophin constructs in both transgenic and viral-mediated gene-transfer models to see whether they could prevent and reverse the disease phenotype, respectively.

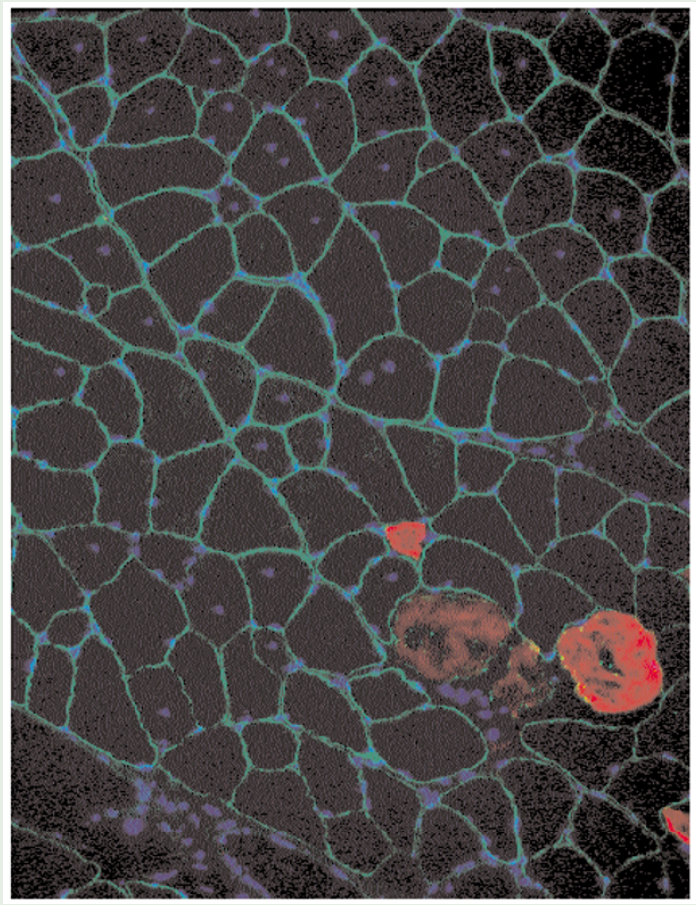

Transgenic $m d x$ mice expressing different micro-dystrophins were protected against damage caused by muscle activity and appeared morphologically identical to normal mice. But the morphologically rescued muscles were weaker than controls. Based on these results, the authors speculate that gene therapy using micro-dystrophins might be effective in preventing ongoing muscle damage, but may not be sufficient to fully restore muscle strength. Interestingly, several of the constructs tested were more effective in preventing dystrophy in diaphragm than limb muscles. The results are relevant to the development of gene therapy of DMD as the diaphragm is the most severely affected muscle in DMD patients, who typically die of respiratory failure.

Another encouraging finding was that viral injection of the dystrophin constructs into dystrophic muscles of immunocompetent mice produced a dramatic reversal of some of the disease-associated changes in muscle fiber morphology. The photograph shows a section of $m d x$ muscle injected with AAV2 micro-dystrophin virus stained by immunofluorescence. Micro-dystrophin, which localizes to the cell membrane, is labeled green and nuclei are labeled blue (DAPI stain). The red staining represents Evans blue dye (EBD) and indicates muscle-membrane permeability, a characteristic feature of dystrophic fibers. In their study (reported on pages 253-261), Harper et al. found a decrease in EBD staining in muscles injected with the micro-dystrophin constructs compared with untreated muscle. More importantly, the injected muscles displayed far fewer centrally nucleated fibers, and had significantly more uniform fiber diameters than uninjected muscles. 